\title{
MEMBUAT PROGRAM DATA BASE TIKET KERETA API DENGAN BORLAND DELPHI
}

\section{DAPOK NOPRIANSYAH 165100074}

Fakultas Komputer, 448757237

dapoknopriansyah.student@umitra.ac.id

\begin{abstract}
Bab ini menjelaskan mengenai proses pengujian dan pembahasan terhadap Aplikasi Sistem Informasi Jadwal Kereta Api dan Pemesanan Tiket Berbasis J2ME yang berjalan, serta tampilan program setelah dieksekusi.
\end{abstract}

Kata Kunci : MEMBUAT PROGRAM DATA BASE TIKET KERETA API DENGAN BORLAND DELPHI

\section{A. INTRODUCTION}

Materi Ke 1

Semakin tidak terasa bahwa perkembangan ilmu pengetahuan

dan teknologi demikian pesatnya, sehingga hampir segala aktifitas

kerja manusia di dukung oleh teknologi. Hal ini terus menyeret dan memacu kita untuk masuk dalam lingkaran alam kecanggihan tersebut.

Oleh karena itu kita di pacu untuk berkualitas dan kreatif dalam berkarya untuk menghasilkan sesuatu yang berguna bagi diri sendiri maupun dapat

dirasakan manfaatnya bagi orang.

Salah satu perkembangan yang paling pesat saat ini adalah perkembangan teknologi mobile atau telepon seluler. Telepon seluler sebagai salah satu maha karya anak manusia dalam bidang komunikasi, memang tidak dapat terlepas dari kehidupan masyarakat modern seperti 
sekarang. Dengan harga murah dan fungsinya yang sangat penting, maka

tidak mengherankan telepon seluler menjadi primadona dalam masyarakat baik itu masyarakat kelas atas hingga bawah. Telepon seluler atau yang

sering kita sebut dengan handphone mampu berkomunikasi dengan content yang tidak terbatas pada suara, melainkan gambar, film, atau sembarang data

digital dapat dilewatkan melalui jalur komunikasi seluler. Lebih jauh teknologi seluler memungkinkan handphone untuk berkomunikasi dengan internet dalam memberikan informasi yang cepat dan efisien.

Sun Microsystem, sebuah perusahaan perangkat lunak menyertakan

teknologi J2ME (Java 2 Micro Edition) untuk membangun dan menjalankan program Java dalam komputer-komputer mini yang memiliki

kapasitas memori dan pemrosesan yang relatif rendah dibandingkan

kapasitas yang dimiliki sebuah PC. Dengan adanya dukungan GPRS dari

pesawat handphone, memungkinkan user untuk dapat mengakses semua

informasi yang disajikan dalam internet ke layar telepon seluler.
Penerapan Teknologi Informasi (TI) saat ini telah menyebar hampir

di semua bidang tidak terkecuali di bidang transportasi darat khususnya kereta api. Transportasi darat dengan kereta api sebagai salah satu alat

transportasi yang cepat dan murah, banyak menjadi pilihan utama

masyarakat umum untuk aktifitas bepergian sehari-hari. Namun sebagai salah satu alat transportasi yang digemari masyarakat modern, sistem

pemberitahuan jadwal serta pemesanan tiket kereta masih menggunakan

metode lama yaitu data perjalanan yang dituliskan pada papan

pengumuman, sehingga sistem yang berjalan kurang efisien. Meskipun saat

ini telah ada sistem pemberitahuan melalui media cetak, namun di rasa

masih memiliki kekurangan di beberapa hal. Sedangkan untuk pemesanan

tiket sendiri, user memiliki beberapa alternatif yaitu melakukan pemesanan

tiket pemesanan secara langsung, pemesanan melalui telepon atau

pemesanan melalui agen-agen. Namun sistem tersebut juga kurang efisien

karena topologi daerah Indonesia yang luas sedangkan letak stasiun yang 


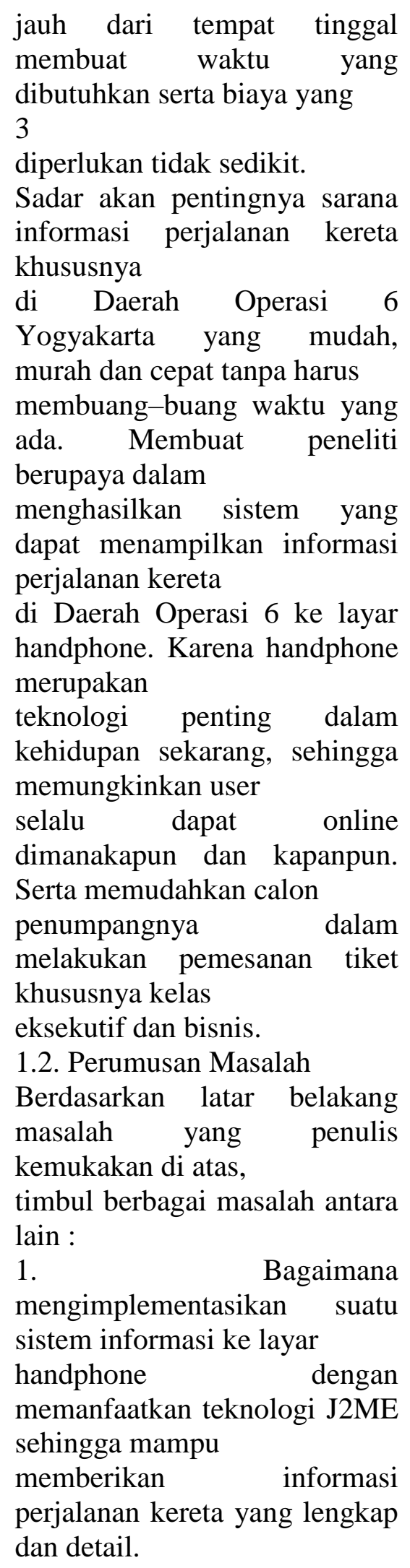

2. Bagaimana membangun aplikasi yang mampu memberikan informasi

melainkan juga mampu melakukan pemesanan ke server.

3. Bagaimana menggabungkan teknologi J2ME dengan bahasa pemrograman PHP dan database MySQL.

4. Bagaimana merancang suatu aplikasi sistem informasi yang sederhana,

mudah digunakan, bermanfaat serta mudah dikelola oleh pegawai terkait.

\section{B. CONCLUSION}

Kesimpulan dari materi ini adalah materi ini berisi uraian tentang kesimpulan yang di dapat dari proses pembuatan Aplikasi Sistem Informasi Jadwal Kereta Api dan Pemesanan Tiket Berbasis J2ME di Daerah Operasi 6, serta saran yang dapat penulis berikan apabila sistem ini ingin dikembangkan lebih lanjut. Unsur-unsur yang harus diperhatikan dan dijadikan prioritas utama untuk perbaikan PT.KAI di stasiun tanjung karang kota Bandar lampung berdasarkan hasil perhitungan diagram kartesius antara lain ketepatan jadwal berangkat dan tiba kereta api, ketepatan waktu proses pembelian tiket, kenyamanan ruang tunggu di stasiun tanjung karang, ketersediaan sarana 
perlengkapan pelayanan (WC/toilet dan kantin).

Didalam kereta, keamanan tempat pelayanan terhadap keberadaan calok, kesopanan, dan keramahan oleh petugas pelayanan. Sedangkan unsurunsur yang lain perlu dipertahankan dan ditingkatkan agar pelayanan nya dapat sesuai dengan harapan masyarakat.

Indeks kepuasan masyarakat terhadap jasa pelayanan $\mathrm{pt}$. KAI di stasiun tanjung karang kota Bandar lampung mencapai 63.25. capai indeks kepuasan ini masuk dalam nilai interval koveksi 62.51-81.25 dengan kategori "baik".

C. ACKNOWLEDGEMENT University Of Indonesia University Of Mitra Indonesia Telkom University University Of Mellbourne Saitama University

\section{REFERENCE (Based ISO 690 )}

[1] A. S. Putra And O. M. Febriani, "Knowledge Management Online Application In Pdam Lampung Province," In Prosiding International Conference On Information Technology And Business
(Icitb), 2018, Pp. 181-187.

[2] A. S. Putra, O. M. Febriani, And B. Bachry, "Implementasi Genetic Fuzzy System Untuk Mengidentifikasi Hasil Curian Kendaraan Bermotor Di Polda Lampung," J. Sist. Inf. Dan Manaj. Basis Data, Vol. 1, No. 1, Pp. 21-30, 2018.

[3] O. M. Febriani And A. S. Putra, "Sistem Informasi Monitoring Inventori Barang Pada Balai Riset Standardisasi Industri Bandar Lampung," J. Inform., Vol. 13, No. 1, Pp. 90-98, 2014.

[4] Putra, Arie Setya. "2018 Artikel Struktur Data, Audit Dan Jaringan Komputer." (2018).

[5] Putra, A. S. (2018, July 17). Paperplain Fundamental Create Application With Borland Delphi 7.0 University Of Mitra Indonesia. Retrieved From Osf.Io/Pbrn9.

\section{E. REFERENCE (Based APA)}

Putra, A. S., Aryanti, D. R., \& Hartati, I. (2018, November). Metode SAW (Simple Additive Weighting) sebagai Sistem Pendukung Keputusan Guru Berprestasi (Studi Kasus: SMK Global Surya). In Prosiding Seminar Nasional Darmajaya (Vol. 1, No. 1, pp. 85-97). 
Sari, D. P., Febriani, O. M., \& Putra, A. S. (2018, November). Perancangan Sistem Informasi SDM Berprestasi pada SD Global Surya. In Prosiding Seminar Nasional Darmajaya (Vol. 1, No. 1, pp. 289-294).

Putra, A. S. (2018). Paperplain: Execution Fundamental Create Application With Borland Delphi 7.0 University Of Mitra Indonesia.

Putra, A. S., Sukri, H., \& Zuhri, K. Sistem Monitoring Realtime Jaringan Irigasi Desa (JIDES) Dengan Konsep Jaringan Sensor Nirkabel. IJEIS (Indonesian Journal of Electronics and Instrumentation Systems), 8(2), 221232.

Darmawan, A., Yuliawati, D., Marcella, O., \& Firmandala, R. (2016). Sistem Absensi dan Pelaporan Berbasis Fingerprint dan SMS Gateway. EXPLORE, 7(1).

Febriani, O. M., Wahyuni, T., \& Yusuf, S. (2017). DESIGN OF WEBSITE-BASED INFORMATION SYSTEM FOR EDOCUMENT ADMINISTRASI IN THE COMMUNITY SERVICE UNIT (A Case Study at Rajabasa District). INTERNATIONAL JOURNAL OF COMPUTERS \& TECHNOLOGY, 16(7), 7010-7020.

Febriani, O. M., \& Wahyuni, T. (2017, October). PERANCANGAN SISTEM E-DOCUMENT ADMINISTRASI LOGBOOK PENELITIAN PADA UNIT LAYANAN DI BANDAR LAMPUNG. In Prosiding Seminar
Nasional Darmajaya (Vol. 1, No. 1, pp. 187-194).

Febriani, O. M., \& Permadi, A. B. (2017). Implementasi Sistem Aplikasi Data Bimbingan dan Pelanggaran Siswa pada Sekolah Menengah Atas di Lampung Tengah dengan Metode Analisis dan Desain Sistem Terdistribusi (SSAD). EXPERT, 7(1).

Febriani, O. M., \& Ambarwati, L. (2015). PERANCANGAN APLIKASI PENGOLAHAN DATA PENJUALAN UKM KELANTING KHAS TELO DESA SIDOHARJO KECAMATAN JATI AGUNG KABUPATEN LAMPUNG SELATAN. Jurnal Teknologi Informasi dan Bisnis Pengabdian Masyarakat Darmajaya, 1(1), 77-95.

Febriani, O. M. (2015). Rancang Bangun Aplikasi Ecommercemenggunakan Freewebstore pada UKM Kelanting di Desa Sidoharjo Lampung Selatan. Prosiding Sembistek 2014, 1(02), 446-458. 